Biomechanical and proteomic analysis of INF- $\beta$-treated astrocytes

This content has been downloaded from IOPscience. Please scroll down to see the full text. 2009 Nanotechnology 20455106

(http://iopscience.iop.org/0957-4484/20/45/455106)

View the table of contents for this issue, or go to the journal homepage for more

Download details:

IP Address: 130.237.165.40

This content was downloaded on 03/10/2015 at 15:13

Please note that terms and conditions apply. 


\title{
Biomechanical and proteomic analysis of INF- $\beta$-treated astrocytes
}

\author{
Daniele Vergara $^{1}$, Roberta Martignago ${ }^{2}$, Stefano Leporatti $^{1}$, \\ Stefania Bonsegna ${ }^{3}$, Giuseppe Maruccio ${ }^{1}$, Franco De Nuccio ${ }^{2}$, \\ Angelo Santino ${ }^{3}$, Roberto Cingolani ${ }^{1}$, Giuseppe Nicolardi ${ }^{2}$, \\ Michele Maffia ${ }^{2,4,5}$ and Ross Rinaldi ${ }^{1,5}$ \\ ${ }^{1}$ National Nanotechnology Laboratory of CNR-INFM, ISUFI, University of Lecce, \\ Italian Institute of Technology (IIT) Research Unit, via Arnesano, I-73100 Lecce, Italy \\ 2 Department of Biological and Environmental Sciences and Technologies, \\ University of Salento, via Monteroni, I-73100 Lecce, Italy \\ ${ }^{3}$ Institute of Sciences of Food Production CNR, Unit of Lecce I-73100, Italy \\ ${ }^{4}$ Laboratory of Clinical Proteomic, 'Vito Fazzi’ Hospital, ASL-Lecce I-73100, Italy \\ E-mail: michele.maffia@unile.it and ross.rinaldi@unile.it
}

Received 12 August 2009

Published 16 October 2009

Online at stacks.iop.org/Nano/20/455106

\begin{abstract}
Astrocytes have a key role in the pathogenesis of several diseases including multiple sclerosis and were proposed as the designed target for immunotherapy.

In this study we used atomic force microscopy (AFM) and proteomics methods to analyse and correlate the modifications induced in the viscoleastic properties of astrocytes to the changes induced in protein expression after interferon- $\beta$ (IFN- $\beta$ ) treatment.

Our results indicated that IFN- $\beta$ treatment resulted in a significant decrease in the Young's modulus, a measure of cell elasticity, in comparison with control cells. The molecular mechanisms that trigger these changes were investigated by $2 \mathrm{DE}$ (two-dimensional electrophoresis) and confocal analyses and confirmed by western blotting. Altered proteins were found to be involved in cytoskeleton organization and other important physiological processes.
\end{abstract}

S. Supplementary data are available from stacks.iop.org/Nano/20/455106

\section{Introduction}

Interferon-beta (IFN- $\beta$ ) is a pleiotropic cytokine with a disease-modifying effect in patients with multiple sclerosis (MS) $[1,2]$. The exact mechanism by which IFN- $\beta$ mediates its activity has been the object of study in several works [3]. However, its action on the central nervous system (CNS) is still debated and not completely elucidated. In the CNS, all three predominant cell types, neurons, oligodendrocytes and astrocytes, act as IFN- $\beta$ producers and responders [4]. Here, we will focus our attention on astrocytes, whose key role in the pathogenesis of several diseases, including multiple sclerosis [5], suggested them as the designed target for immunotheraphy.

5 Authors to whom any correspondence should be addressed.
Some principal ways have been proposed to explain how IFN exerts its effects on astrocytes, it acts by regulating astrocyte proliferation and survival [6-11] and by inhibiting nitric oxide (NO) production [12, 13]. In addition, IFN treatment induces soluble factor release that stimulates oligodendrocyte and neuron survival [9] and modulates the immune functions of astrocytes as demonstrated both in vivo and in vitro [14-16].

IFN- $\beta$ also attenuates astrocyte proliferation induced by different mitogens [7, 9]. Moreover, it has been proposed that the beneficial effects of IFN- $\beta$ in MS therapy could be due to the ability of the drug to regulate foetal and neonatal astrocyte survival through phosphatidylinositol 3-kinase (PI$3 \mathrm{~K}) /$ Akt and p38 MAPK pathways $[6,8,11]$. In fact, the addition of IFN- $\beta$ in the medium of serum-starved foetal astrocytes reduces the number of apoptotic cells [6] as well as 
pre-treatment of astrocytes with IFN- $\beta$ prevents the cytotoxic effect of tumour necrosis factor (TNF) [8].

IFN- $\alpha / \beta$ causes inhibition of mitochondrial cytochrome $\mathrm{C}$ oxidase by impairing the subsequent production of $\mathrm{NO}$ mediated by IFN- $\gamma$ [12] and it is beneficial to neurones as it prevents mitochondrial damage mediated by NO [13].

Cytoskeletal proteins and the plethora of proteins that regulate its organization are the mediators and/or effectors in different signalling pathways and may therefore be involved in the IFN- $\beta$ action. Cytoskeleton is a complex network of actin filaments, microtubules and intermediate filaments, which supports cell structure and with a role in a variety of processes such as apoptosis, migration and invasion. The cytoskeleton is also believed to contribute to the biomechanical properties of cells [17]. The mechanical properties of living cells have been investigated extensively for some years with different techniques including AFM, magnetic tweezers and micropipette aspiration [18].

AFM, invented in 1986 by Binnig, has emerged as an high resolution imaging method to characterize biological samples as well as living cells in their liquid environment. The potential of this technique to reveal the overall mechanical properties of biological systems was demonstrated in a large variety of studies [19-22].

In this work, we evaluated the effects of IFN- $\beta$ on cultures of control rat astrocytes by using a combination of different experimental approaches. Proteomics profiling and western blotting analysis were employed to gain insight into the molecular mechanisms of IFN- $\beta$ action in astrocytes. Atomic force microscopy (AFM) was used to determine the changes in the mechanical properties of these cells induced by IFN- $\beta$ treatment.

Results showed a modification of cytoskeletal organization and cell elasticity after IFN- $\beta$ treatment as confirmed by atomic force microscopy and confocal analysis.

\section{Materials and methods}

\subsection{Rat astrocytes culture protocol and treatment}

Astrocyte cultures were prepared from 27 newborn Wistar rats (1-2 days old) according to the method of McCarthy and De Vellis [23]. Briefly, cerebral hemispheres of newborn Wistar rat pups were isolated aseptically, meninges were removed and placed in a $\mathrm{Ca}^{2+}$ - and $\mathrm{Mg}^{2+}$-free balanced salt solution (CMF-BSS) pH 7.4, cleaned and mechanically dissociated by sequential passage through a Pasteur pipette. Suspended cells were plated at a density of $5 \times 10^{4}$ cells $\mathrm{cm}^{-2}$ onto $75 \mathrm{~cm}^{2}$ flasks or Petri dishes pre-treated with poly-L-lysine containing Dulbecco's modified Eagle's medium (DMEM) supplemented with $10 \%$ foetal bovine serum (FBS), $2 \mathrm{mM}$ glutamine, $20 \mathrm{U} \mathrm{ml}^{-1}$ penicillin, $25 \mu \mathrm{g} \mathrm{ml}^{-1}$ streptomycin and $5 \mathrm{mg} \mathrm{ml}^{-1}$ fungizone, and maintained in $5 \% \mathrm{CO}_{2} 95 \%$ air at $37^{\circ} \mathrm{C}$. Medium was changed every $3-4$ days and shaken manually to remove non-adherent cells.

After 3-4 weeks of cultures cells with 70-80\% confluence were treated with $100 \mathrm{U} \mathrm{ml}^{-1}$ IFN- $\beta$ (Sigma) for $24 \mathrm{~h}$. Control cells were left untreated.

\subsection{Immunofluorescence}

Astrocytes were characterized and detected in culture by immunofluorescence using a monoclonal antibody against glial fibrillary acidic protein (GFAP) and revealed with corresponding secondary antibody conjugated with a red quantum dot (Invitrogen) by using the avidin-streptavidin method [24]. More than $95 \%$ of cells in culture were astrocytes.

For confocal microscopy analysis, cells were fixed for 5 min with $3.7 \%$ formaldehyde in phosphate-buffered saline (PBS) solution, permeabilized with a $0.1 \%$ solution of Triton $\mathrm{X}-100$ in PBS followed by $30 \mathrm{~min}$ incubation at room temperature with phalloidin-TRITC (Sigma). After that, cells were washed three times in PBS.

Immunofluorescent anti- $\beta$ tubulin staining was performed according to the manufacturer's protocol (Sigma). For nuclear staining, fixed cells were incubated with $1 \mu \mathrm{g} \mathrm{ml}^{-1}$ of Hoechst 33342 for $5 \mathrm{~min}$ at room temperature. The preparations were mounted in $50 \%$ glycerol in PBS.

Images were acquired by laser confocal microscopy using an TCS SP5 (Leica Microsystem GmbH, Mannheim, Germany).

\subsection{Atomic force microscopy analysis}

An atomic force microscope (Bioscope 2, Veeco Instruments Inc. Santa Barbara, CA, USA), mounted on an inverted optical microscope (Zeiss Observer Z1, Carl Zeiss, Göttingen, Germany), was used to investigate morphological and mechanical properties of astrocytes treated with IFN- $\beta$. Contact mode images of living cells were obtained by using $\mathrm{V}$-shaped $\mathrm{Si}_{3} \mathrm{~N}_{4}$ cantilevers with a nominal spring constant of $0.01 \mathrm{~N} \mathrm{~m}^{-1}$ (MLCT-AUNM, Veeco) at a resolution of 512 data points per line and a scan rate of $0.3 \mathrm{~Hz}$. The experimental spring constant was determined using the standard thermal noise calibration method [25].

Living cells were analysed at $37^{\circ} \mathrm{C}$ in Leibovitz culture medium as previously described [26]. Briefly, Young's moduli of control and treated cells were determined by acquiring point-by-point force versus distance curves over $128 \times 128$ arrays. The tip velocity for these measurements was maintained below $1 \mu \mathrm{m} \mathrm{s}^{-1}$ to limit hysteresis [27]. The sensitivity of the photodetector was calibrated by acquiring force versus distance curves on a clean plastic Petri dish. Data on extending force curves were analysed by applying the Hertz model [28] and by considering Sneddon's variation [29].

A home-written MatLab (MathWorks, Natick, MA) program was used to obtain elasticity maps. For comparison an indentation depth less than $10 \%$ of the cell thickness [30], $200 \mathrm{~nm}$, was chosen for calculating the characteristic Young's modulus and was averaged for each single cell. In the present work, we define the contact point from the deflection versus indentation (distance) curve as the point where the slope (i.e. $k$ ) increases by $20 \%$ with respect to the initial value. 


\subsection{Two-dimensional gel electrophoresis $(2 D E)$ and MALDI-TOF analysis}

Astrocytes were detached with $0.5 \%$ trypsin and washed twice with a Tris-buffered sucrose solution $\left(250 \mathrm{mmol}^{-1}\right.$ sucrose in $10 \mathrm{mmol}^{-1}$ Tris, $\mathrm{pH} \mathrm{7).}$

The cell pellet was suspended in rehydration buffer containing $7 \mathrm{M}$ urea, 2 thiourea, $4 \%$ CHAPS and a protease inhibitor cocktail (Sigma) and lysed by sonication. Protein concentration was determined using the Bradford protein assay (BioRad).

Protein samples $(80 \mu \mathrm{g})$ were mixed up to $250 \mu \mathrm{l}$ of rehydration buffer (7 M urea, 2 thiourea, 4\% CHAPS, $65 \mathrm{mM}$ DTT and $0.5 \% \mathrm{v} / \mathrm{v}$ IPG buffer, GE Healthcare) and applied to an IPG strip (13 cm, pH 3-10 NL, GE Healthcare). IEF and second dimension was performed with IPGphor IEF and Hoefer SE 600 Ruby electrophoresis (GE Healthcare) as previously described [31]. The IPG-strips were loaded and run on a $12 \%$ SDS-PAGE gel at constant current of $20 \mathrm{~mA} / \mathrm{gel}$ until the bromophenol blue dye front had run off the base of the gel.

Gels were fixed overnight in fixing solution $(30 \% \mathrm{v} / \mathrm{v}$ ethanol and $10 \% \mathrm{v} / \mathrm{v}$ acetic acid), rinsed $10 \mathrm{~min}$ in water and then incubated in sensitizing solution (sodium acetate $0.5 \mathrm{M}$, glutaraldehyde $2 \%$ ) for $30 \mathrm{~min}$. Gels were washed three times with Milli-Q water for $10 \mathrm{~min}$ each, sensitized for $10 \mathrm{~min}$ in $0.05 \%$ naphthalene disulfonate and stained in $0.1 \%$ silver ammonia solution for $30 \mathrm{~min}$ and developed for $10 \mathrm{~min}$ in an acidic developer. The developing reaction was terminated by incubation in stopping solution (5\% acetic acid) for $10 \mathrm{~min}$ followed by three washing steps. Gels were scanned by Image Master scanner at $300 \mathrm{dpi}$ and analysed by Image Master software 5.0.

For mass spectrometry identification a preparative $2 \mathrm{DE}$ gel was realized by using about $500 \mu \mathrm{g}$ of the cell lysate. Gels were stained with a mass spectrometry compatible silver staining [32]. Spots showing a statistically significant differential expression were selected for analysis with a Bruker Reflex IV mass spectrometer in positive reflection mode. Briefly, spots were manually excised from the gel, destained with $\mathrm{H}_{2} \mathrm{O}_{2}$ and subjected to in-gel tryptic digestion. Trypsindigested protein samples were desalted and concentrated by Zip Tip tips (Zip Tip C18 micro, Millipore) and loaded on the MALDI target, using the $\alpha$-cyano-4-hydroxycinnamic acid as a matrix.

Proteins were identified by using peptide mass fingerprinting (PMF) as stated previously [31]. Searches were restricted to Rattus, peptide mass tolerance was set to $50 \mathrm{ppm}$ and possible modifications (fixed modifications: carbamidomethylated Cys; variable modifications: oxidized Met) were taken into consideration. Search parameters allowed for one missed cleavage site.

\subsection{Western blotting}

Whole cell lysates (in lysis buffer as described above) containing $10 \mu \mathrm{g}$ (GFAP and VIME) and $30 \mu \mathrm{g}$ of total proteins (COF1, COF1 pser3 and PROF1) were diluted in cold RIPA buffer, resolved on $12 \%$ sodium dodecyl sulfate
Table 1. Mean surface roughness of control and treated cells. (Note: abbreviations: $R_{\mathrm{a}}$ : average roughness; $R_{\mathrm{q}}$ : root-mean-square roughness; $P<0.05$.)

\begin{tabular}{lll}
\hline Group & $R_{\mathrm{a}}(\mathrm{nm})$ & $R_{\mathrm{q}}(\mathrm{nm})$ \\
\hline Control & $339.5 \pm 97.6$ & $423.3 \pm 124.1$ \\
IFN $\left(100 \mathrm{U} \mathrm{ml}^{-1}, 24 \mathrm{~h}\right)$ & $230.2 \pm 94.1$ & $295.5 \pm 113.4$ \\
\hline
\end{tabular}

polyacrylamide gels (Mini Protean II electrophoresis system, BioRad) and blotted onto nitrocellulose membranes. The membranes were blocked with $5 \% \mathrm{w} / \mathrm{v}$ non-fat dry milk in TBS containing $0.1 \%$ Tween-20 (Sigma) and probed with selected primary antibodies overnight at $4{ }^{\circ} \mathrm{C}$. After incubation with secondary antibodies, immunoblots were visualized with the ECL detection kit (Amersham Biosciences). Actin was used as an internal control and was detected with an anti-actin mouse antibody (Sigma).

Western blotting with a monoclonal antibody against neuron-specific $\alpha$-tubulin excluded neuron contamination.

\subsection{Statistical analysis}

The resulting data were exported to Graph Pad Prism. The Mann-Whitney $U$ test was used to test for significant differences. All data are given as means \pm standard deviations (SD). Differences between groups were evaluated using the Krustal-Wallis test, Dunn's post-test was also performed. A value of $P<0.05$ was considered statistically significant.

\section{Results}

\subsection{Morphology of astrocytes in culture}

To determine the overall cellular characteristics of cultured astrocytes, cells were imaged under a phase-contrast microscope and by a combination of AFM and immunolabelling.

A representative AFM deflection image of astrocytes is shown in figure 1. Cells exhibited an evident large cell region with three to five main cytoplasmatic processes, several finer processes and a prominent oval or round nucleus $(14.13 \mu \mathrm{m} \pm$ $2.71 \mu \mathrm{m})$. The cytoplasmatic region was characterized by filamentous actin structure, as revealed at higher magnification in the AFM image (figure 1(B)) and by F-actin staining (figure 1(D)), and by membranous elevations (figure 1(B)).

Overall, cell morphology (shape, volume, surface area) was not drastically influenced by IFN- $\beta$ treatment; however, other cellular parameters appeared modified. As showed in table 1 both average roughness $\left(R_{\mathrm{a}}\right)$ and the root-mean-square roughness $\left(R_{\mathrm{q}}\right)$ decreased after IFN treatment.

Additionally, we did not detect any changes in cell viability following IFN- $\beta$ treatment using Hoechst staining (figure $\mathrm{S} 1$ of supporting information available at stacks.iop.org/Nano/20/455106).

\subsection{Measurement of Young's modulus}

Young's modulus was used as a parameter to relate the changes induced by IFN- $\beta$ on the cytoskeletal structure with the biomechanical properties of astrocytes. The results showed 

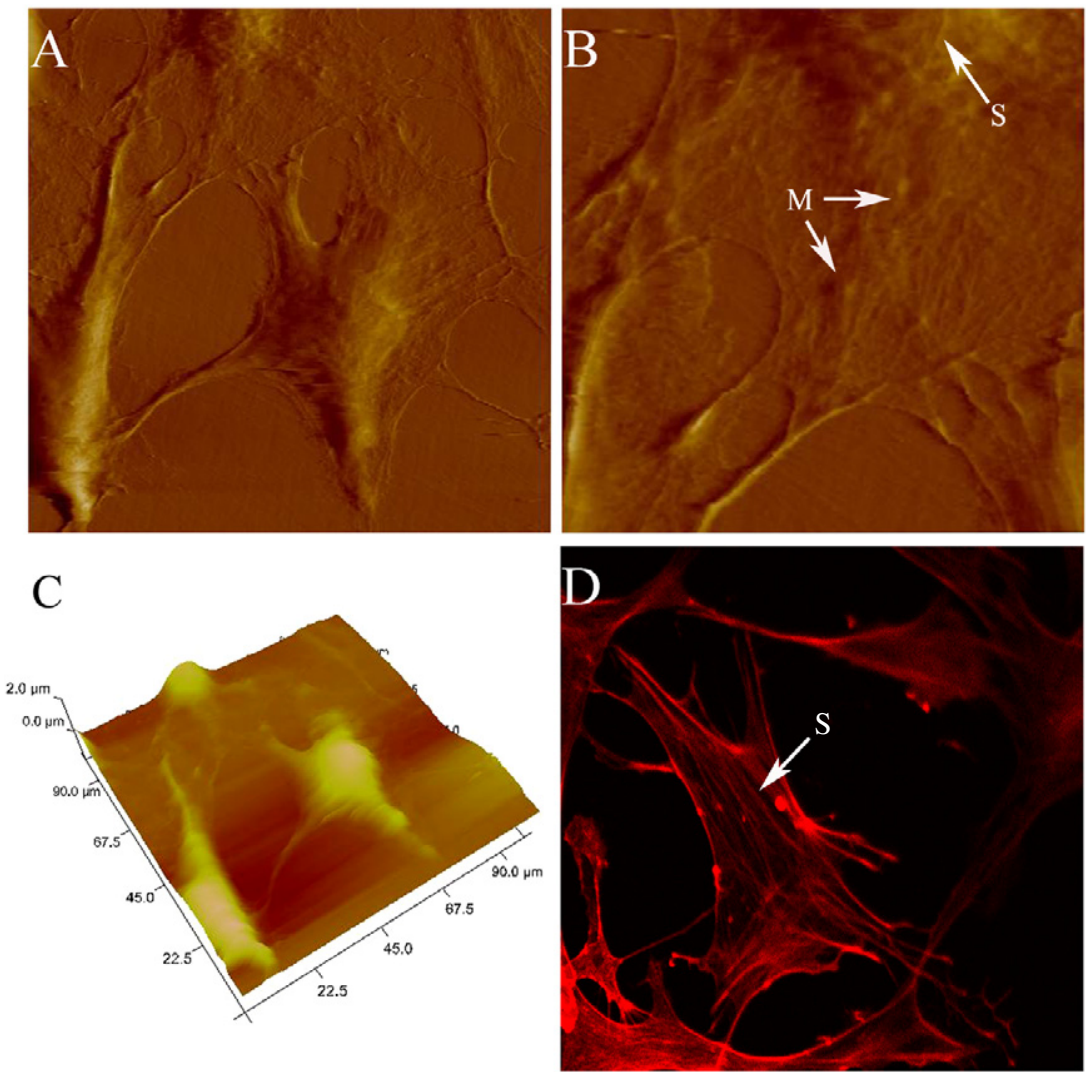

Figure 1. Correlation of AFM and confocal images. (A) The AFM topography image of living astrocytes at $37^{\circ} \mathrm{C}$ (scan size $100 \mu \mathrm{m}$ ) with the three-dimensional morphologies (C). (B) Deflection image at higher magnification (scan size $40 \mu \mathrm{m}$ ) showing several cytoskeletal structures and filaments underneath the cell membrane. (D) F-actin network labelled with rhodamine phalloidin. Astrocytes show numerous cytoplasmic actin filaments that radiate out from the nucleus and extend into the major cell processes. Arrows indicate membranous elevations (M) and stress fibre (S) bundles of actin filaments.
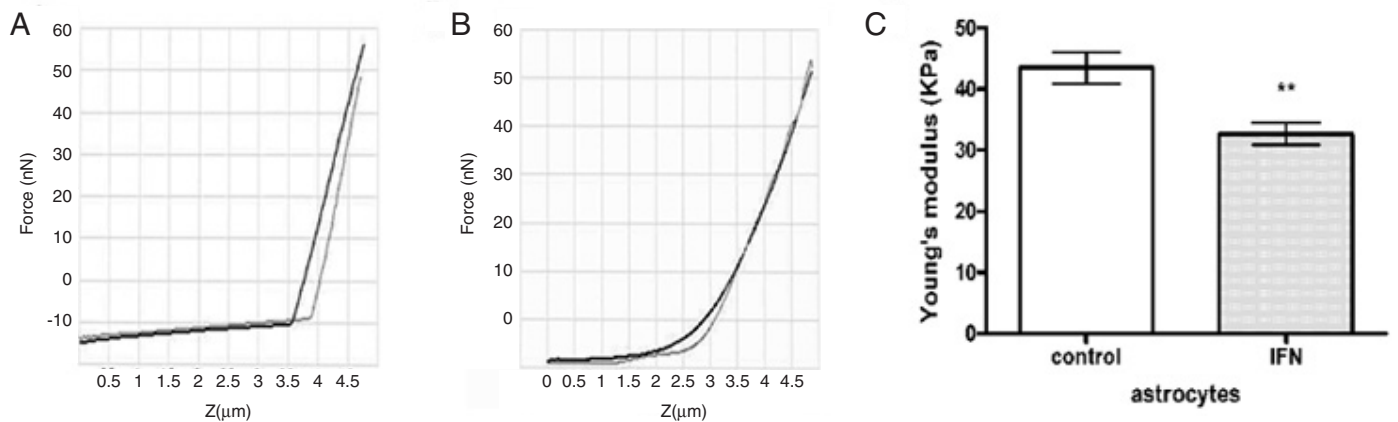

Figure 2. Representative force versus $Z$ position measured in liquid for the substrate (A) and cell (B). The approach and retraction force curves are shown in black and grey, respectively. (C) Histograms showing the mean value and the distribution of Young's moduli measured for control and treated $\left(100 \mathrm{U} \mathrm{ml}^{-1}\right.$ of IFN- $\left.\beta\right)$ astrocytes $\left(P<0.01^{* *}\right)$.

that IFN treatment changed the elastic properties of astrocytes. The treatment with $100 \mathrm{U} \mathrm{ml}^{-1}$ IFN- $\beta$ resulted in a $25 \%$ reduction of the mean Young's modulus in comparison with untreated cells (figures 2 and 3). Data were obtained from 50 cells representative of each group $(n=3$ independent experiments).

Figure 2 shows representative examples of the forcedistance curves. The atomic force microscope tip begins to scan the sample far above from it, corresponding to the position on the left side of the plot. As the tip came into contact with the sample (moving to the right along the plots), the cantilever is deflected from its equilibrium position (region on the right). Figure 2 shows how cellular stiffness was significantly lower (B) with respect to the Petri dish (A). Force-distance curves were measured on the cell area above the nucleus to exclude the influence of the substrate in the determination of the elastic modulus (figure $\mathrm{S} 2$ of supporting information available at stacks.iop.org/Nano/20/455106). Figure 3 shows a typical 


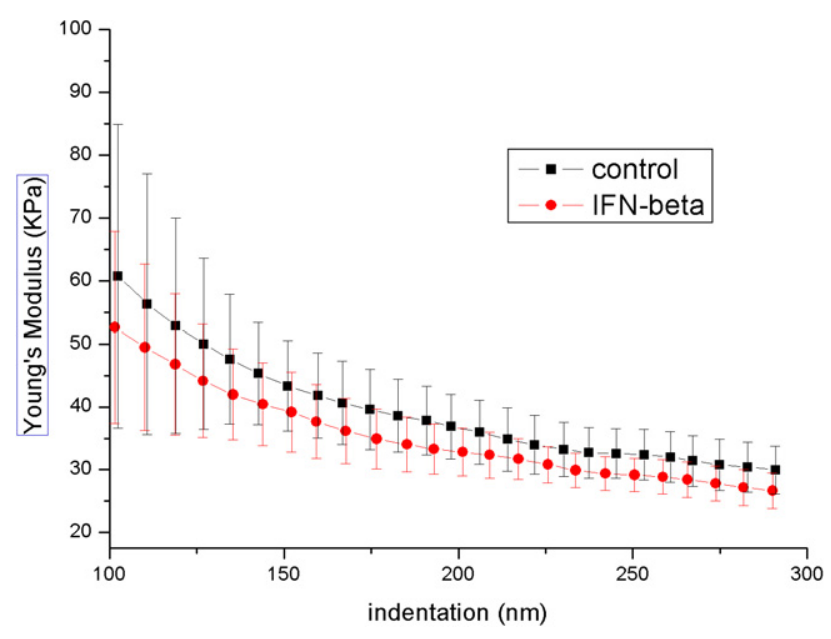

Figure 3. Characteristic Young's modulus of control and

IFN- $\beta$-treated cells grown on a Petri dish as a function of indentation depth. AFM measurements were taken on the nuclear region.

behaviour of Young's modulus as a function of indentation depth averaged on a single cell (control and IFN- $\beta$-treated). At an indentation of $200 \mathrm{~nm}$ (chosen for comparison for the whole astrocyte population since it is typically less than $10 \%$ of cell thickness) a significant decrease of Young's modulus between control and IFN- $\beta$-treated astrocytes is clearly detected.

\subsection{Cytoskeletal organization of cells treated with IFN- $\beta$}

In order to assess the effects of IFN- $\beta$ on cytoskeletal (re)organization, the contribution of actin filaments and tubulin microtubules was studied in either control and IFN- $\beta$-treated $\left(100 \mathrm{U} \mathrm{ml}^{-1}\right.$ for $\left.24 \mathrm{~h}\right)$ cells. Astrocytes cultured in the presence of IFN- $\beta$ exhibited visible changes in the organization of Factin filaments. Under normal growth conditions, cells showed an evident network of actin stress fibres extending across the entire cell body. In treated cells, F-actin filaments were less organized with a diffuse actin staining (figure 4).

Immunofluorescence analysis of tubulin, using a specific anti-tubulin- $\beta$ antibody, revealed a clear and organized distribution in either control or treated cells, even though a more intense staining was evident in treated cells (figure 5).

\subsection{Proteomic and western blotting analysis of astrocytes before and after IFN- $\beta$ treatment}

Figures 6(A) and (B) show representative silver-stained gels performed over a 3-10 pI range from control and treated
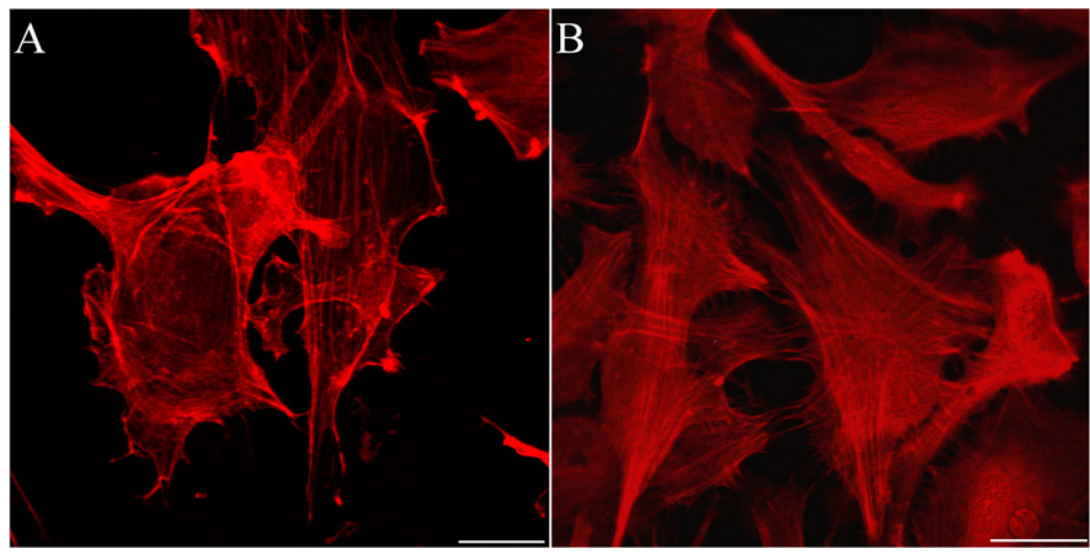

Figure 4. Confocal microscopy images of actin filaments. Control cells (A) and treated cells (100 $\mathrm{U} \mathrm{ml}^{-1}$ of IFN- $\beta$ ) (B) were fixed and fluorescence labelling with rhodamine phalloidin was carried out. The images shown are representative of at least three independent experiments. Scale bar $25 \mu \mathrm{m}$.
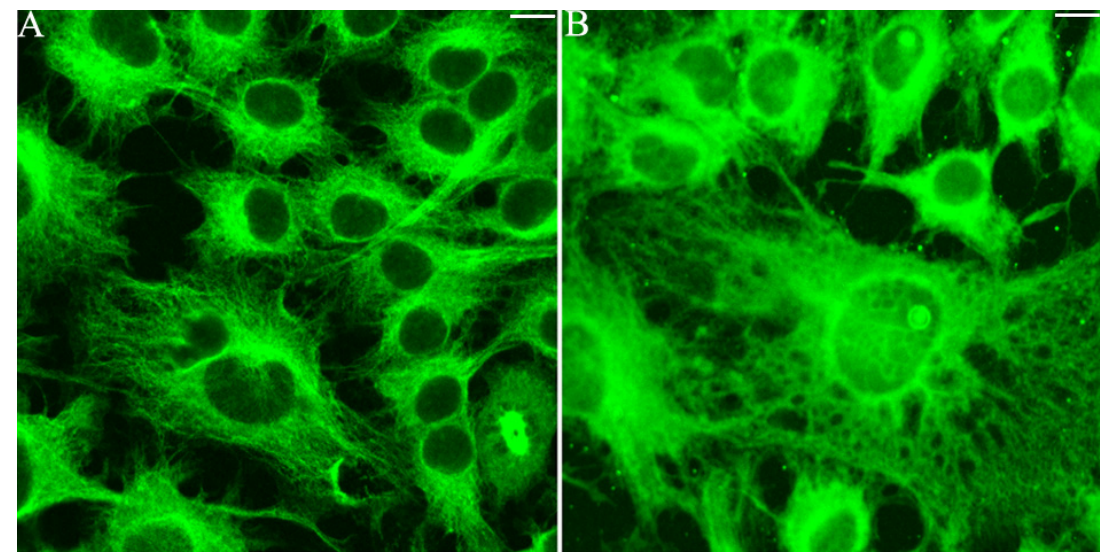

Figure 5. Control cells (A) and treated cells $\left(100 \mathrm{U} \mathrm{ml}^{-1}\right.$ of IFN- $\beta$ ) (B) were processed for confocal microscopy using an antibody directed to $\beta$-tubulin. The images shown are representative of at least three independent experiments. Scale bar $10 \mu \mathrm{m}$. 


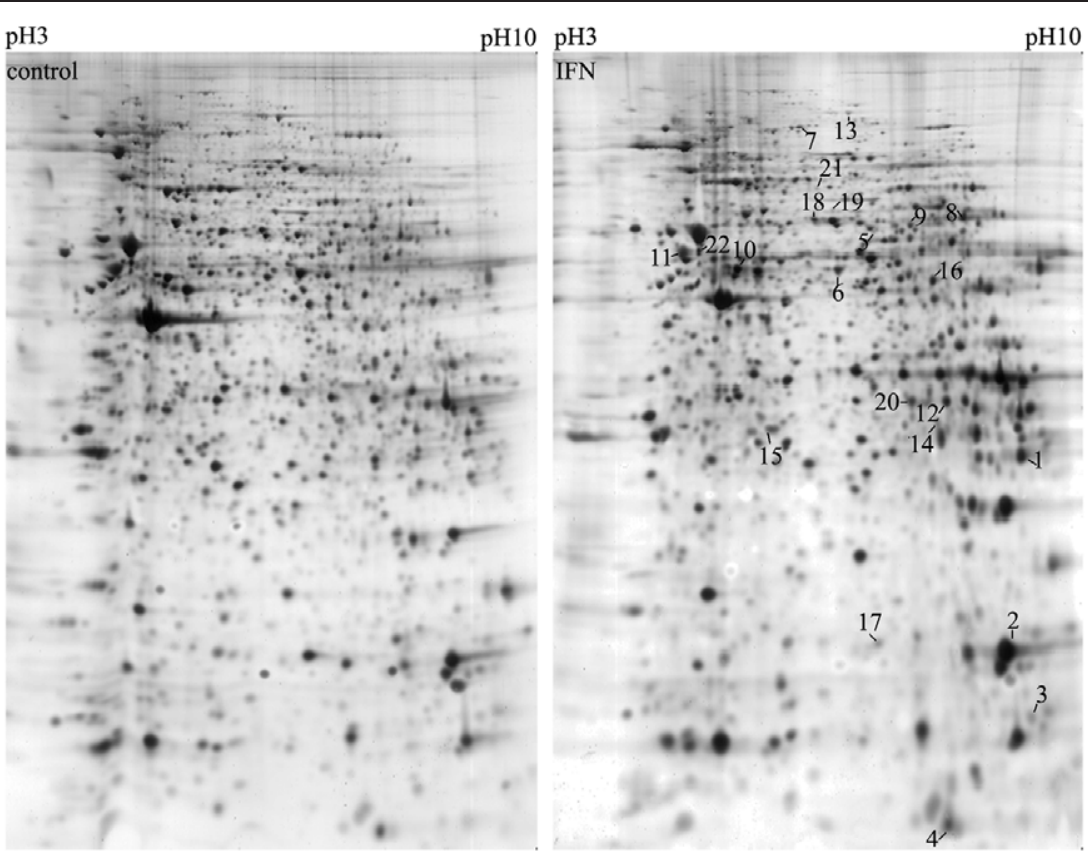

Figure 6. Silver-stained reference $2 \mathrm{DE}$ gel of astrocytes showing differentially expressed proteins. Ten biological replicates were analysed for each experimental condition. The $\mathrm{pH}$ gradient in the first dimension range from 3 to 10 , while the second dimension was a $12 \%$ gradient polyacrylamide gel. All the differentially expressed proteins are marked on the map and listed in table 2.

astrocytes. After spot detection, $1326 \pm 123$ and $1328 \pm$ 181 gel spots were identified in treated and control samples, respectively. By comparing IFN- $\beta$-treated samples with control ones, we were able to identify 22 differentially expressed spots. In particular, the expression of 17 protein spots increased and that of 5 spots decreased, as shown in figure S3 of supporting information (available at stacks.iop.org/Nano/20/455106). Differentially expressed spots were subjected to MALDI-TOF PMF analysis allowing the identification of 23 different proteins. The same protein, cofilin-1, was identified in two different spots (spots 2 and 17), indicating a possible post-translational modification. The successfully identified proteins corresponding to up-or downregulated spots are listed in table 2 .

We carried out western blot analysis to confirm the reliability of the quantitative data obtained by $2 \mathrm{DE}$ results (figure 7). We focused our attention on five differentially expressed proteins: GFAP, vimentin, cofilin-1, cofilin-1 pser3 and profilin-1, potentially involved in cytoskeleton reorganization and biomechanical modifications after IFN- $\beta$ treatment. In all cases, the results agreed with those obtained by $2 \mathrm{DE}$ confirming the higher expression of these proteins in treated astrocytes. Immunoblot analyses were replicated two times.

\section{Discussion}

In this study, we used AFM to investigate the stiffness of cultured astrocytes after IFN- $\beta$ treatment. Furthermore, the biological explanation for these results was provided by confocal microscopy, 2DE and confirmed by western blot analysis.
Our goal was to find out potential protein candidates that can account for the observed stiffening response by using the potential of $2 \mathrm{DE}$ to separate thousands of proteins simultaneously. To our knowledge, this is the first time that a proteomic approach has been integrated into AFM studies.

Our results indicated that treatment of astrocytes with IFN- $\beta$ significantly reduced the Young's modulus of living cells. Since the cellular elastic modulus is greatly influenced by cytoskeletal structure and cellular shape, we studied how the organization of these structures can be affected by IFN$\beta$ treatment. Our analysis suggests that the observed change in the elastic properties of astrocytes could be a consequence of the resulting cytoskeletal reorganization in response to IFN- $\beta$ treatment, rather than a result of some morphological modifications of astrocytes.

To confirm this hypothesis, we first investigated the morphology and the surface structure of treated astrocytes. AFM images revealed that IFN- $\beta$ treatment did not change the overall cell morphology in vitro, even though it modified the cellular roughness. Indeed, the cellular surface of astrocytes treated with IFN- $\beta$ was smoother than control cells. Several studies focused their attention on the impact of surface roughness on cell morphology or proliferation, but until now only a few of them took into account the effects of drug treatment on modifications of cellular roughness [33]. The plasma membrane is intimately linked to the cytoskeleton and possible modifications in the cytoskeletal architecture underneath could have an important role in roughness changes. Using confocal microscopy we demonstrated a different cytoskeletal organization of IFN$\beta$-treated cells. Immunofluorescence analysis of F-actin and tubulin- $\beta$ revealed rearrangements in the organization of 
Table 2. List of differentially expressed proteins modified after IFN- $\beta$ treatment and identified by MALDI-TOF analysis. Swiss-Prot database was used for database searching.

\begin{tabular}{|c|c|c|c|c|c|c|}
\hline $\begin{array}{l}\text { Spot } \\
\text { number }\end{array}$ & Protein name and Swiss-Prot entry name & $\begin{array}{l}\text { Accession } \\
\text { number }\end{array}$ & pI/MW (Da) & $\begin{array}{l}\text { Sequence } \\
\text { coverage }\end{array}$ & $\begin{array}{l}\text { Number } \\
\text { peptides }\end{array}$ & $\begin{array}{l}\text { Mowse } \\
\text { score }\end{array}$ \\
\hline 1 & Glutathione S-transferase Mu 1 (GSTM1_RAT) & P04905 & $8.3 / 25914$ & $55 \%$ & 14 & 119 \\
\hline 2 & Cofilin-1 (COF1_RAT) & P45592 & $8.2 / 18533$ & $48 \%$ & 8 & 77 \\
\hline 3 & Profilin-1 (PROF1_RAT) & P62963 & $8.5 / 14957$ & $36 \%$ & 5 & 90 \\
\hline 4 & Ubiquitin (UBIQ_RAT) & P62989 & $6.6 / 8565$ & $69 \%$ & 6 & 66 \\
\hline 5 & Selenium binding proteins (SBP1_RAT) & Q8VIF7 & $6.1 / 52532$ & $34 \%$ & 12 & 123 \\
\hline 6 & Rab GDP dissociation inhibitor beta (GDIB_RAT) & P50399 & $5.9 / 50538$ & $32 \%$ & 25 & 173 \\
\hline 7 & $\begin{array}{l}\text { Alpha glucosidase } 2 \text { alpha neutral subunit } \\
\text { (GANAB_MOUSE) }\end{array}$ & Q8BHN3 & $5.7 / 90857$ & $28 \%$ & 17 & 154 \\
\hline 8 & Adenylyl cyclase-associated protein 1 (CAP1_RAT) & Q08163 & $7.2 / 51589$ & $25 \%$ & 11 & 97 \\
\hline 9 & Cytosol aminopeptidase (AMPL_RAT) & Q68FS4 & 56150 & $23 \%$ & 8 & 83 \\
\hline 10 & Glial fibrillary acidic protein (GFAP_RAT) & P47819 & $5.4 / 49957$ & $33 \%$ & 12 & 107 \\
\hline 11 & $\begin{array}{l}\text { Tubulin beta-2A chain (TBB2A_RAT)/Tubulin } \\
\text { beta- } 2 \text { B chain (TBB2B_RAT) }\end{array}$ & P85108/Q3KRE8 & $4.8 / 49907 / 49954$ & $51 \%$ & $17 / 16$ & $127 / 114$ \\
\hline 12 & Glyceraldehyde-3-phosphate dehydrogenase (G3P_RAT) & P04797 & $8.1 / 35828$ & $25 \%$ & 6 & 77 \\
\hline 13 & Vinculin (VINC_RAT) & P85972 & $5.8 / 116616$ & $24 \%$ & 25 & 151 \\
\hline 14 & Nitrilase homolog 2 (NIT2_RAT) & Q497B0 & $6.9 / 30701$ & $40 \%$ & 9 & 82 \\
\hline 15 & Proteasome activator complex subunit 1 (PSME1_RAT) & Q63797 & $5.8 / 28577$ & $38 \%$ & 12 & 109 \\
\hline 16 & $\begin{array}{l}\text { Isocitrate dehydrogenase [NADP] cytoplasmic } \\
\text { (IDHC_ RAT) }\end{array}$ & P41562 & $6.5 / 46735$ & $35 \%$ & 14 & 98 \\
\hline 17 & Cofilin-1 (COF1_ RAT) & P45592 & $8.2 / 18533$ & $48 \%$ & 8 & 95 \\
\hline 18 & $\begin{array}{l}\text { Protein disulfide-isomerase } \mathrm{A} 3 \text { precursor (PDIA3_ } \\
\mathrm{RAT} / \text { Interferon-induced GTP binding protein } \\
M \times 1\end{array}$ & P11598/P18588 & $5.9 / 56624 ; 6.5 / 74470$ & $28 \% / 14 \%$ & $14 / 7$ & $128 / 100$ \\
\hline 19 & T-complex protein 1 subunit alpha (TCPA_RAT) & P28480 & $5.9 / 60360$ & $37 \%$ & 13 & 90 \\
\hline 20 & $\begin{array}{l}\text { Delta(3,5)-Delta(2,4)-dienoyl-CoA isomerase, } \\
\text { mitochondrial [Precursor] (ECH1_RAT) }\end{array}$ & Q62651 & $8.1 / 36172$ & $36 \%$ & 12 & 82 \\
\hline 21 & Dihydropyrimidinase-related protein 2 (DPYL2_RAT) & P47942 & $6.0 / 62278$ & $17 \%$ & 9 & 124 \\
\hline 22 & Vimentin (VIME_RAT) & P31000 & $5.1 / 53733$ & $40 \%$ & 15 & 190 \\
\hline
\end{tabular}

these cytoskeletal components within astrocytes (see figures 4 and 5).

A relationship between actin cytoskeletal modifications and alterations of the elastic modulus was also reported. By using cytoskeleton-disrupting chemicals, it has been found that disrupting F-actin filaments by cytochalasin D resulted in a decrease of cell stiffness [34]. Furthermore, the contribution of F-actin to the elastic modulus could also be influenced by its organization into bundles or networks [35], a process under the control of various groups of functionally specialized actin binding proteins (ABPs). Proteomic analyses on whole cell proteins let us to demonstrate that the expression of several members of these protein families were modified by IFN- $\beta$ treatment. Among these, the role of cofilin-1 and profilin-1 in the reorganization of the cytoskeleton after IFN- $\beta$ treatment could be pivotal considering their cellular functions. Cofilin is the principal actin depolymerizing protein, whose activity is regulated by its phosphorylation/dephosphorylation on a highly conserved serine residue, Ser 3 [36]. This phosphorylation inhibits protein activity by reducing its affinity for actin by 20 -fold [37].

The binding of cofilin to actin severs the existing actin filaments and regulates their dynamics and torsional flexibility [38, 39]. Cofilin also appears to modulate the elastic properties of actin by reducing significantly its elastic modulus, playing an essential role in determining the mechanical properties of actin cytoskeleton [40].

Another actin binding protein, profilin-1, has the capacity to catalyze the exchange of actin monomer-coupled ADP for
ATP and hence to activate G-actin. Profilin-1 is a ubiquitous protein found in many eukaryotic systems and plays a role both in signal transduction pathways and in actin filament dynamics [41, 42]. It is among the first actin binding proteins characterized in the literature [43]. Profilin-1 is not only an important regulator of F-actin dynamics in the cell [44], but it is also able to bind monomeric actins (G-actin) and hence to inhibit or promote actin filament assembly $[45,46]$ also in synergy with cofilin-1 [47].

The increased levels of cofilin-1, profilin-1 and the decreased phosphorylation of cofilin-1 which can finally enhance the actin filament dissociating capacity of this protein are consistent with an increased dynamism of the subcortical actin network in IFN- $\beta$-treated astrocytes. Both proteins acted by promoting the reorganization of actin that occurred in response to IFN- $\beta$ treatment by regulating the availability of cellular actin monomers for actin filament organization as observed by confocal microscopy.

In addition, 2DE analysis did not shown any significant changes in the expression of actin isoforms, confirming how IFN- $\beta$ altered actin filaments by regulating only its polymerization/organization status.

Other cytoskeletal proteins were found to increase their expression after IFN- $\beta$ treatment, including tubulin- $\beta$, GFAP and vimentin. In particular, GFAP and vimentin belong to the class of intermediate filaments and were both over-expressed after IFN- $\beta$ treatment, as confirmed by $2 \mathrm{DE}$ and western blot. These proteins have a central role in the crosstalk between 


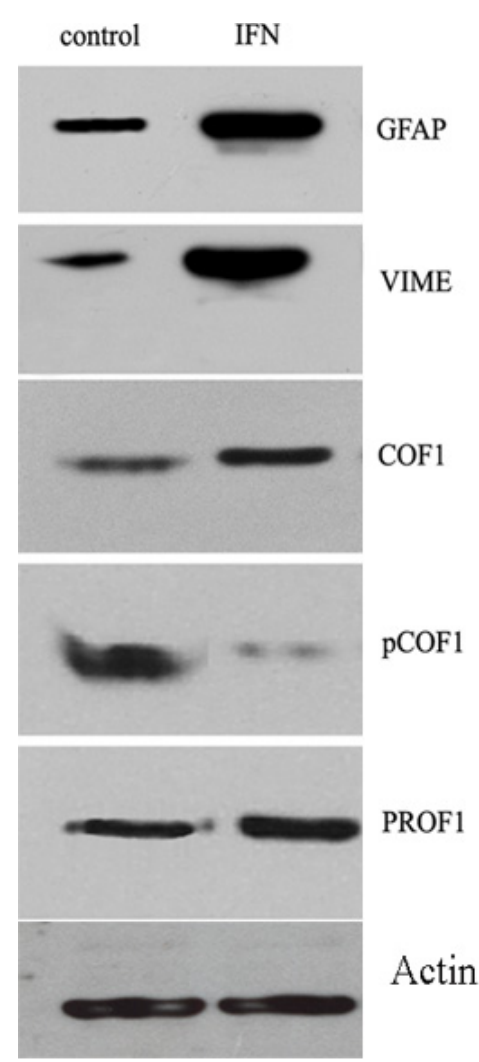

Figure 7. Western blot characterization of GFAP, vimentin, cofilin-1, cofilin-1 pser3 and profilin-1. Protein lysates were prepared from control cells, cells treated with $100 \mathrm{U} \mathrm{ml}^{-1} \mathrm{IFN}-\beta$ for $24 \mathrm{~h}$. Actin was examined to assess protein loading. The bands were visualized using an ECL system. The proteins are located at 50, 54, 18, 18 and $15 \mathrm{kDa}$, respectively.

microtubules and actin filaments [48] and can influence cell stiffening [49].

We cannot exclude a role for these proteins in determining the elastic properties of treated astrocytes, but their direct involvement can be clearly assessed only by silencing their gene products. However, it has been demonstrated that cells lacking the expression of microfilaments showed alterations in their cell morphology and vitality that could affect their stiffness [49].

GFAP and vimentin are also considered markers of astrocytes gliosis that occur and increase in expression after brain injury. Our results demonstrated an increase of astrocytes GFAP and vimentin levels also after IFN- $\beta$ treatment, without any exposure to gliotic stimuli. Astrocyte activation after brain injury could be considered both a positive and negative event, depending on the type and extent of the damage, as well as the time point. Astrocytes form a glial barrier around a lesion site, which prevents the axonal regrowth after an injury (non-permissive gliosis), but at the same time isolates the intact CNS tissue from secondary lesions and, in certain conditions, could provide a permissive substratum for neuritic extension (permissive gliosis) [50]. So, the presence of reactive astrocytes (as we showed by increasing GFAP and Vimentin expression levels after IFN- $\beta$ treatment) could represent a favourable event for neural regrowth and repair [51], for example considering the lesions typical of MS, for which
IFN- $\beta$ is one of the most used drugs. Further studies may better clarify how cellular stiffness could interfere on the development of a permissive regenerative core.

The influence of microtubules on cell rigidity is still not clearly elucidated. Microtubules can modulate the stiffness of cardiomyocytes against shear stress [52] but they do not seem to modulate the stiffening of fibroblast treated with taxol [34].

In summary, IFN- $\beta$ acts by modifying the elastic properties of astrocytes as a result of the modification of several proteins involved in the cytoskeletal structure and organization. Our results provide direct evidence that cofilin-1 and profilin1 are involved in the global remodelling of cytoskeleton after IFN- $\beta$ treatment by increasing the treadmilling of peripheral actin filaments. Overexpression of microtubules and intermediate filaments suggests a role of other cytoskeletal components in determining the elastic properties of IFN- $\beta$ treated astrocytes.

\section{Acknowledgments}

We are grateful to Dr Antonio Danieli for his technical support and Dr Raffaele Acierno for help with Maldi-Tof. This work has been supported by the Italian National Programme FIRB RBNEFO3MCJ_ 003 and by the Apulia Region explorative project 'Control system of the evolution of the neurological diseases based on image analysis' PE_ 061 .

\section{References}

[1] Trojano M et al 2007 New natural history of interferon-beta-treated relapsing multiple sclerosis Ann. Neurol. 61 300-6

[2] Kappos L et al 2006 Long-term subcutaneous interferon beta-1a therapy in patients with relapsing-remitting MS Neurology 67 944-53

[3] Javed A and Reder A T 2006 Therapeutic role of beta-interferons in multiple sclerosis Pharmacol. Ther $11035-56$

[4] Paul S, Ricour C, Sommereyns C, Sorgeloos F and Michiels T 2007 Type I interferon in the central nervous system Biochimie 89 770-8

[5] Nair A, Frederick T J and Miller S D 2008 Astrocytes in multiple sclerosis: a product of their environment Cell. Mol. Life Sci. 65 2702-20

[6] Barca O, Ferré S, Seoane M, Prieto J M, Lema M, Señarís R and Arce V M 2003 Interferon beta promotes survival in primary astrocytes through phosphatidylinositol 3-kinase J. Neuroimmunol. 139 155-9

[7] Malik O, Compston D A and Scolding N J 1998 Interferon-beta inhibits mitogen induced astrocyte proliferation in vitro J. Neuroimmunol. 86 155-62

[8] Barca O, Costoya J A, Señarís R M and Arce V M 2008 Interferon- $\beta$ protects astrocytes against tumour necrosis factor-induced apoptosis via activation of $\mathrm{p} 38$ mitogen-activated protein kinase Exp. Cell. Res. $3142231-7$

[9] Satoh J, Paty D W and Kim S U 1996 Counteracting effect of IFN-beta on IFN-gamma-induced proliferation of human astrocytes in culture Mult. Scler. $1279-87$

[10] Satoh J and Kuroda Y 2001 Differing effects of IFN beta vs IFN gamma in MS: gene expression in cultured astrocytes Neurology 57 681-5

[11] Barca O, Seoane M, Ferré S and Prieto J M 2007 Mechanisms of interferon- $\beta$-induced survival in fetal and neonatal primary astrocytes Neuroimmunomodulation 14 39-45 
[12] Stewart V C, Giovannoni G, Land J M, McDonald W I, Clark J B and Heales S L 1997 Pretreatment of astrocytes with interferon-alpha/beta impairs interferon-gamma induction of nitric oxide synthase $J$. Neurochem. $682547-51$

[13] Stewart V C, Land J M, Clark J B and Heales S J 1998 Pretreatment of astrocytes with interferon-alpha/beta prevents neuronal mitochondrial respiratory chain damage J. Neurochem. $70432-4$

[14] Tedeschi B, Barrett J N and Keane R W 1986 Astrocytes produce interferon that enhances the expression of $\mathrm{H}-2$ antigens on a subpopulation of brain cells J. Cell. Biol. 102 2244-53

[15] Barna B P, Chou S M, Jacobs B, Yen-Lieberman B and Ransohoff R M 1989 Interferon-beta impairs induction of HLA-DR antigen expression in cultured adult human astrocytes J. Neuroimmunol. 23 45-53

[16] Zanon R G and Oliveira A L 2006 MHC I upregulation influences astroglial reaction and synaptic plasticity in the spinal cord after sciatic nerve transaction Exp. Neurol. 200 521-31

[17] Kasza K E, Rowat A C, Liu J, Angelini Th E, Brangwynne C P, Koenderink G H and Weit D A 2007 The cell as a material Curr. Opin. Cell. Biol. 19 101-7

[18] Lima C T, Zhoua E H and Quek S T 2006 Mechanical models for living cells-a review J. Biomech. 39 95-216

[19] Leporatti S, Gerth A, Köhler G, Kohlstrunk B, Hauschildt S and Donath E 2006 Elasticity and adhesion of resting and lipopolysaccharide-stimulated macrophages FEBS Lett. $\mathbf{5 8 0} 450-4$

[20] Kliche K, Kuhn M, Hillebrand U, Ludwig Y, Stock C and Oberleithner H 2006 Direct aldosterone action on mouse cardiomyocytes detected with atomic force microscopy Cell. Physiol. Biochem. 18 265-74

[21] Chouinard J A, Grenier G, Khalil A and Vermette P 2008 Oxidized-LDL induce morphological changes and increase stiffness of endothelial cells Exp. Cell. Res. 314 3007-16

[22] Sato M, Suzuki K, Ueki Y and Ohashi T 2007 Microelastic mapping of living endothelial cells exposed to shear stress in relation to three-dimensional distribution of actin filaments Acta Biomater. 3 311-19

[23] McCarthy K D and de Vellis J 1980 Preparation of separate astroglial and oligodendroglial cell cultures from rat cerebral tissue J. Cell. Biol. 85 890-902

[24] Pathak S, Davidson M C and Silva G A 2007 Characterization of the functional binding properties of antibody conjugated quantum dots Nano Lett. 7 1839-45

[25] Butt H J and Jaschke M 1995 Calculation of thermal noise in atomic force microscopy Nanotechnology 6 1-7

[26] Leporatti S, Vergara D, Zacheo A, Vergaro V, Maruccio G, Cingolani R and Rinaldi R 2009 Cytomechanical and topological investigation of MCF-7 cells by scanning force microscopy Nanotechnology 20055103

[27] Mathur A B, Collinsworth A M, Reichert W M, Kraus W E and Truskey G A 2001 Endothelial, cardiac muscle and skeletal muscle exhibit different viscous and elastic properties as determined by atomic force microscopy. J. Biomech. 34 1545-53

[28] Hertz H 1881 Über die Berührung fester elastischer Körper J. Reine Angew. Math. 92 156-71

[29] Sneddon I N 1965 The relation between load and penetration in the axisymmetric Boussinesq problem for a punch of arbitrary profile Int. J. Eng. Sci. 3 47-57

[30] Mahaffy R E, Shih C K, MacKintosh F C and Käs J 2000 Scanning probe-based frequency-dependent microrheology of polymer gels and biological cells Phys. Rev. Lett. 85 880-3

[31] Vergara D, Chiriacò F, Acierno R and Maffia M 2008 Proteomic map of peripheral blood mononuclear cells Proteomics 8 2045-51
[32] Mortz E, Krogh T N, Vorum H and Görg A 2001 Improved silver staining protocols for high sensitivity protein identification using matrix-assisted laser desorption/ionization-time of flight analysis Proteomics 1 1359-63

[33] Wang X P, Chen T S, Sun L and Cai J Y 2008 Live morphological analysis of taxol-induced cytoplasmic vacuoliazation in human lung adenocarcinoma cells Micron 39 1216-21

[34] Rotsch C and Radmacher M 2000 Drug-induced changes of cytoskeletal structure and mechanics in fibroblasts: an atomic force microscopy study Biophys. J. 78 520-35

[35] Gardel M L, Shin J H, MacKintosh F C, Mahadevan L, Matsudaira P and Weitz D A 2004 Elastic behavior of cross-linked and bundled actin networks Science 304 1301-5

[36] Moriyama K, Iida K and Yahara I 1996 Phosphorylation of Ser-3 of cofilin regulates its essential function on actin Genes Cells $173-86$

[37] Ressad F, Didry D, Xia G X, Hong Y, Chua N H, Pantaloni D and Carlier M F 1998 Kinetic analysis of the interaction of actin-depolymerizing factor (ADF)/cofilin with G- and F-actins. Comparison of plant and human ADFs and effect of phosphorylation J. Biol. Chem. 273 20894-902

[38] Pavlov D, Muhlrad A, Cooper J, Wear M and Reisler E 2007 Actin filament severing by cofilin J. Mol. Biol. 365 1350-8

[39] Prochniewicz E, Janson N, Thomas D D and De la Cruz E M 2005 Cofilin increases the torsional flexibility and dynamics of actin filaments J. Mol. Biol. 353 990-1000

[40] McCullough B R, Blanchoin L, Martiel J L and De la Cruz E M 2008 Cofilin increases the bending flexibility of actin filaments: implications for severing and cell mechanics J. Mol. Biol. 381 550-8

[41] Schlüter K, Jockusch B M and Rothkegel M 1997 Profilins as regulators of actin dynamics Biochim. Biophys. Acta 1359 97-109

[42] Carlsson L, Nystrom L E, Sundkvist I, Markey F and Lindberg U 1977 Actin polymerizability is influenced by profilin, a low molecular weight protein in non-muscle cells J. Mol. Biol. 115 465-83

[43] Pollard T D and Cooper J A 1986 Actin and actin-binding proteins. A critical evaluation of mechanisms and functions Ann. Rev. Biochem. 55 987-1035

[44] Stossel T P 1989 From signal to pseudopod. How cells control cytoplasmic actin assembly J. Bio. Chem. 264 18261-4

[45] Kang F, Purich D L and Southwick F S 1999 Profilin promotes barbed-end actin filament assembly without lowering the critical concentration J. Biol. Chem. 274 36963-72

[46] Pantaloni D and Carlier M F 1993 How profilin promotes actin filament assembly in the presence of thymosin beta $4 \mathrm{Cell}$ 75 1007-14

[47] Didry D, Carlier M F and Pantaloni D 1998 Synergy between actin depolymerizing factor/cofilin and profilin in increasing actin filament turnover J. Biol. Chem. 273 25602-11

[48] Chang L and Goldman R D 2004 Intermediate filaments mediate cytoskeletal crosstalk Nat. Rev. Mol. Cell. Biol. 5 601-13

[49] Wang N and Stamenović D 2000 Contribution of intermediate filaments to cell stiffness, stiffening, and growth Am. $J$. Physiol. Cell. Physiol. 279 188-94

[50] Ridet J L, Malhotra S K, Privat A and Gage F H 1997 Reactive astrocytes: cellular and molecular cues to biological function Trends Neurosci. 20 570-7

[51] Miller W J, Leventhal I, Scarsella D, Haydon P G, Janmey P and Meaney D F 2009 Mechanically induced reactive gliosis causes ATP-mediated alterations in astrocyte stiffness J. Neurotrauma 26 789-97

[52] Nishimura S, Nagai S, Katoh M, Yamashita H, Saeki Y, Okada J, Hisada T, Nagai R and Sugiura S 2006 Microtubules modulate the stiffness of cardiomyocytes against shear stress Circ. Res. 98 81-7 